\title{
Effect of Surface Roughness on Oxidation Resistance of Stainless Steel AISI 316Ti During Exposure at High Temperature
}

\author{
Wojciech J. Nowak
}

Submitted: 29 July 2020 / Revised: 1 October 2020 / Accepted: 9 October 2020 / Published online: 11 November 2020

\begin{abstract}
In the present work, the influence of surface roughness on oxidation kinetics of AISI 316Ti stainless steel and its consequences in term of oxidation resistance were investigated. Namely, the effect of surface roughness on oxidation resistance was evaluated during different types of cyclic oxidation tests at 900 and $1000{ }^{\circ} \mathrm{C}$. The obtained results revealed that alloy possessing higher surface roughness showed longer lifetime compared to that with lower surface roughness. It was also found that more severe cyclic conditions suppressed the positive effect of surface roughness on sample's lifetime. The better oxidation resistance of rougher alloy was correlated with suppressed formation of Fe-rich nodules on ground surfaces and explained by the combined effect of introduced defects in the near-surface region and possible increase in residual stresses caused by mechanical surface preparation.
\end{abstract}

Keywords cyclic oxidation test, high temperature oxidation, lifetime, oxidation resistance, stainless steel, thermal shock test

\section{Introduction}

The metallic materials are widely used as construction materials in various sectors in industry. The largest sectors, where metallic materials are widely used, are energy production, aviation and automotive sectors. In all mentioned sectors, the materials face very high temperature. Fe-based alloys are the most commonly used as construction materials. However, the exposure of Fe-based alloys at high temperature results in high temperature gas corrosion. To increase the oxidation resistance, $\mathrm{Cr}$ and $\mathrm{Ni}$ are added into alloys to produce stainless steels. Then, due to high content of $\mathrm{Cr}$, stainless steels can be classified as "chromia" forming alloys (Ref 1), i.e., during the exposure at high temperature, they form slowly growing $\mathrm{Cr}_{2} \mathrm{O}_{3}$ scale, which is protective up to $1050{ }^{\circ} \mathrm{C}$. It was shown that above $1050{ }^{\circ} \mathrm{C}$ chromia scale loses its protective properties due to volatile species formation (Ref 2,3 ). Then, potentially, stainless steels can be successfully used at high temperature. One of the family members of stainless steel is AISI 316Ti. The addition of $\mathrm{Ti}$ enables stabilization of the alloy structure at temperature exceeding $800{ }^{\circ} \mathrm{C}$ (Ref 4). Several studies were performed on stainless steel grade 316, e.g., in supercritical water conditions ( $\operatorname{Ref} 5)$, in water at elevated temperature (Ref $6,7)$, under low temperature carburization conditions ( Ref 8 ) or during low temperature corrosion testing (Ref 9). It is known that increase in operating temperature results in increase of

Wojciech J. Nowak, Department of Materials Science, Faculty of Mechanical Engineering and Aeronautics, Rzeszów University of Technology, Powstanców Warszawy 12, 35-959 Rzeszow, Poland. Contact e-mail: w.nowak@prz.edu.pl.

engine efficiency (Ref 10). Then, oxidation resistance of metallic materials at high temperature has become a point of interest for researchers. The increase in oxidation resistance can be achieved by applying of oxidation resistant coatings like, e.g., aluminide layers (Ref 11-14) or MCrAlY-type coatings (Ref 15-18), however, this is an additional process which generates additional costs. It was already shown that by the simple surface preparation methods resulting in different surface roughness, high temperature oxidation kinetics of metallic materials can be affected (Ref 19-25). The effect of surface preparation of AISI $316 \mathrm{Ti}$ on its wet corrosion resistance was already studied (Ref 26, 27). However, no single work about the effect of surface preparation method resulting in different surface roughness on the oxidation resistance of AISI 316 Ti was performed. Therefore, the aim of the present work is to investigate the influence of surface roughness on high temperature oxidation kinetics of AISI 316 Ti and to evaluate the consequences during cyclic exposure at high temperature.

\section{Materials and Methods}

To investigate the effect of surface geometrical structure on oxidation resistance of stainless steel, namely stainless steel AISI 316Ti with the nominal composition given in Table 1 was chosen. From the block, the rectangular specimens with the dimensions $20 \times 10 \times 2 \mathrm{~mm}$ were machined using spark erosion technique. After cutting, all samples were ground up to 1000 grit $\mathrm{SiC}$ paper. From such prepared samples, part of them was ground using 80 grit abrasive paper, and another part was polished up to mirror like surface finishing using colloidal silica polishing suspension with the grain size $1 \mu \mathrm{m}$. All specimens were ultrasonically cleaned in acetone and dried with pressurized air. Such processing modes of surface preparation have been selected intentionally to obtain different surface roughness for systematic study of the effect of surface roughness on oxidation resistance of AISI 316Ti. Specimens 
Table 1 Nominal and measured chemical composition of AISI 316Ti (given in wt.\%)

\begin{tabular}{|c|c|c|c|c|c|c|c|c|c|}
\hline Element & $\mathbf{C}$ & $\mathbf{S i}$ & Mn & $\mathbf{P}$ & $\mathbf{S}$ & $\mathbf{C r}$ & $\mathbf{N i}$ & Mo & Ti \\
\hline \multicolumn{10}{|c|}{ Chemical composition, wt. $\%$} \\
\hline Nominal & Max. 0.08 & Max. 1.0 & Max. 2.0 & Max. 0.045 & Max. 0.03 & $17.5 \pm 1.0$ & $12.0 \pm 1.5$ & $2.25 \pm 0.25$ & Max. 0.7 \\
\hline Measured (Spark-OES) & 0.04 & 0.6 & 1.9 & 0.011 & 0.01 & 16.6 & 12.1 & 2.04 & 0.4 \\
\hline
\end{tabular}

from each surface preparation method were selected for determination of surface roughness parameters by laser profilometer Sensofar S-Neox non-contact 3D optical profiler. After roughness measurements, samples were subjected to thermogravimetrical oxidation tests in TG furnace XERION Xtube. The oxidation was performed with the heating rate $10 \mathrm{~K}$ min, $21 / \mathrm{min}$ gas flow at $1000{ }^{\circ} \mathrm{C}$ in air up to 48 . In parallel, another sets of specimens, two samples per each surface preparation method, were subjected to two types of cyclic oxidation tests. First type was performed in tube furnace XERION X-tube at 1000 and $900{ }^{\circ} \mathrm{C}$ for which the cycle was consisted of $2.5 \mathrm{~h}$ heating period and $0.5 \mathrm{~h}$ cooling with fan. In this type of test, the samples are placed in the sample holder which is located in quartz tube with the dry air flow of $21 / \mathrm{min}$. The furnace is movable, the sample holder stays at the same position. During the heating, the furnace moves to the position where the sample holder is in the hot zone, while for cooling period furnace moves into the cold zone and fan cools the quartz tube automatically for $0.5 \mathrm{~h}$. The second type of cyclic oxidation test was performed in furnace SCZ 120/150 made by Czylok at $900{ }^{\circ} \mathrm{C}$. In this furnace, more severe cyclic conditions were assumed. The samples were hanged on wires made of Khantall in the sample holder. Contrary to previous situation, in this type of furnace, the sample holder is movable and furnace isn't. Each cycle was consisted of $2 \mathrm{~h}$ heating and 15 min cooling with pressurized air. For heating period, the sample holder automatically moves into the hot zone of the furnace just after the hot zone of furnace reaches set temperature. The temperature in the furnace is controlled by two pyrometers and additionally by thermocouple placed in the center of sample holder. This means that the samples are moved for heating period directly to desired temperature. After $2 \mathrm{~h}$, heating sample holder automatically moves out of the furnace into the cold zone and the samples are immediately cooled using pressurized air. To unify, the first type of cyclic oxidation, consisting of $2.5 \mathrm{~h}$ heating and $0.5 \mathrm{~h}$ cooling will be called as "slow cycling," while more severe cycling oxidation, consisting of $2 \mathrm{~h}$ heating and $15 \mathrm{~min}$ cooling will be labeled as "rapid cycling". For both types of cyclic oxidation tests, the mass of each samples was periodically measured, and the normalized mass change was calculated. Phase composition of the samples was identified using an x-ray diffractometer ARL XTRa from Thermo Fisher company. Filtered copper lamp $(\mathrm{CuK} \alpha$, $\lambda=0.1542 \mathrm{~nm}$ ), with a voltage of $40 \mathrm{kV}$, range $2 \theta=20-20^{\circ}$ and step size $0.02^{\circ} / 3 \mathrm{~s}$ was used. Phase composition was determined using the powder diffraction file (PDF) developed and issued by the ICDD (The International Center for Diffraction Data). The selected samples were subjected to depth profiling using glow discharge optical emission spectrometer (GD-OES) made by Horiba Jobin-Yvon. GD-OES depth profiles were quantified according to procedure described elsewhere (Ref 28-30). After depth profiling, the metallographic cross sections were prepared according to standard procedures. The cross sections were observed with light optical microscope Nikon Epiphot 300 and analyzed by scanning electron microscope Hitachi S3400N. The residual stresses measurement was performed using $\mathrm{x}$-ray diffraction performed on a PROTO iXRD COMBO produced by Proto Manufacturing Ltd.

\section{Results}

\subsection{Surface Roughness Description}

The representative specimens, which were selected from each surface preparation method, were subjected to measurement surface roughness using laser profilometer. Figure 1 shows three-dimensional reproduction of surface topography of polished, 1000 grit and 80 grit prepared samples. Additionally, the roughness parameter $R_{\mathrm{a}}$ calculated from laser profilometry is shown in Fig. 1(a), (b) and (c). It is found that calculated $R_{\mathrm{a}}$ parameter for polished surface is $0.009 \mu \mathrm{m}$, for ground using 1000 grit sandpaper is $0.042 \mu \mathrm{m}$ (one order of magnitude higher as compared to polished surface) and $1.128 \mu \mathrm{m}$ (three orders of magnitude higher as compared to polished surface). It can also be noticed that the scratches originated from grinding are directionally oriented. To unify roughness measurements, roughness parameters were calculated taking into account the perpendicular direction to the grinding direction.

\subsection{Isothermal Oxidation Test at $1000{ }^{\circ} \mathrm{C}$}

The thermogravimetrical (TG) mass change plot shown in Fig. 2 revealed similar mass gain after $48 \mathrm{~h}$ of air exposure at $1000{ }^{\circ} \mathrm{C}$ for both ground samples. The obtained mass change after $48 \mathrm{~h}$ exposure for sample ground by 80 and 1000 grit sandpapers is about $1.5 \mathrm{mg} \mathrm{cm}^{-2}$. Since the final mass change is similar to both ground surfaces, then the curves course is slightly different for aforementioned samples. For sample ground by 80 grit sandpaper, the highest increase in mass change was observed during first $7 \mathrm{~h}$. After this period, the mass change has been stabilized at roughly constant value. In case of mass change of sample ground by 1000 grit sandpaper, two slopes can be distinguished, namely sharp one up to $7 \mathrm{~h}$ and gentle slope between 7 and $48 \mathrm{~h}$. For polished sample, the highest mass change among studied specimens is observed. After $48 \mathrm{~h}$ of exposure about $2.5 \mathrm{mg} \mathrm{cm}^{-2}$ mass gain is observed.

The GD-OES depth profiles depicting elements concentration as a function of sputtering time is shown in Fig. 3. Figure 3(a) shows depth profile obtained on polished AISI $316 \mathrm{Ti}$ after $48 \mathrm{~h}$ of isothermal air exposure. In the GD-OES depth profile of polished surface (Fig. 1a), the external oxide scale is observed as region up to $400 \mathrm{~s}$ of sputtering. Based on depth profile, one can see that the outer oxide scale consists of 


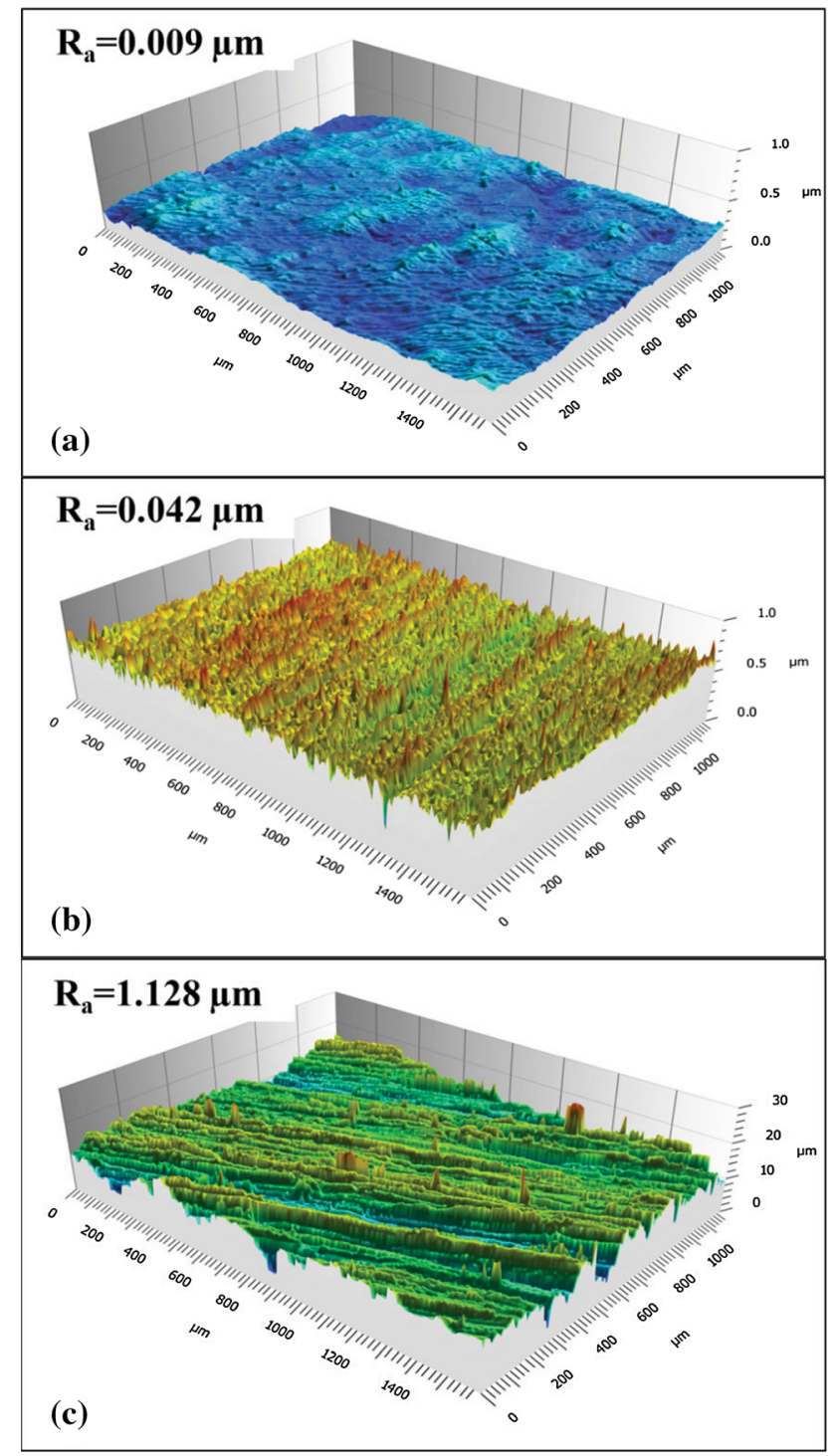

Fig. $13 \mathrm{D}$ images obtained by laser profilometer showing surface topography of AISI $316 \mathrm{Ti}$ prepared by: (a) polishing up to $1 \mu \mathrm{m}$, (b) grinding up to 1000 grit $\mathrm{SiC}$ paper and (c) grinding up to 80 grit sandpaper

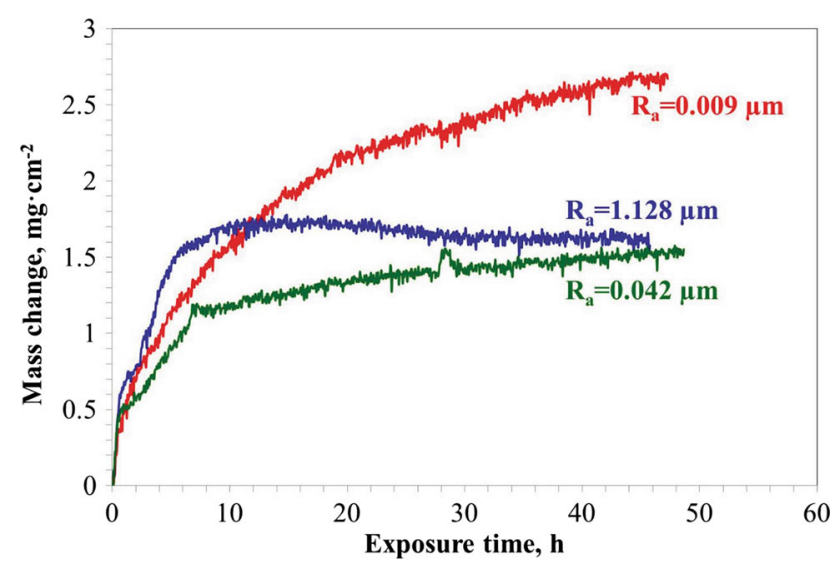

Fig. 2 Normalized mass change plot obtained during isothermal exposure of AISI $316 \mathrm{Ti}$ at $1000{ }^{\circ} \mathrm{C}$ in air for $48 \mathrm{~h}$
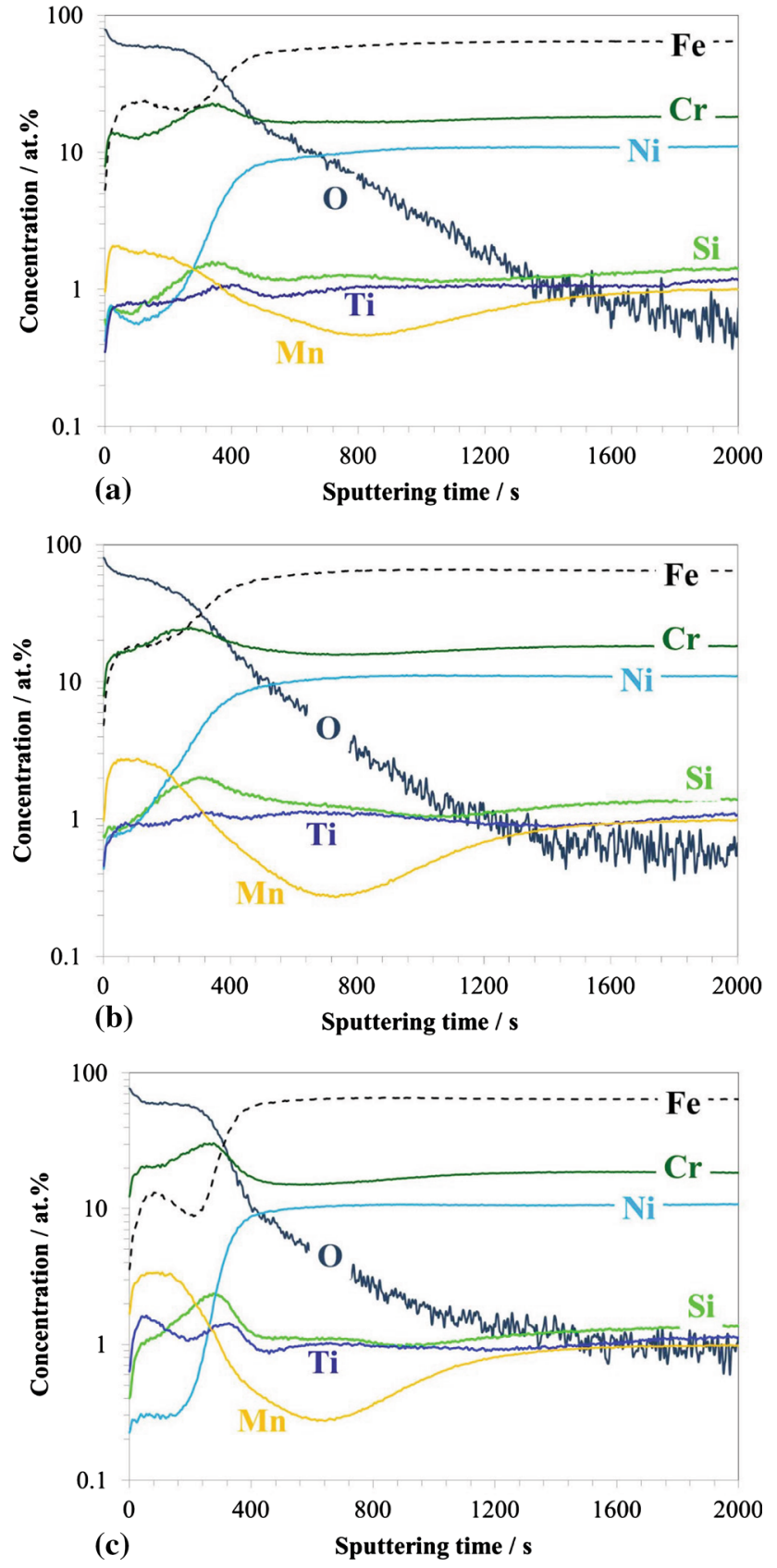

Fig. 3 GD-OES depth profiles obtained on: (a) $1 \mu \mathrm{m}$ polished, (b) 1000 grit and (c) 80 grit ground surface of AISI 316Ti after isothermal exposure at $1000^{\circ} \mathrm{C}$ in air

mixture of chromium and iron oxide. The depth profile revealed that in the very outer part of the oxide scale higher content of $\mathrm{Fe}$ than $\mathrm{Cr}$ is observed. In the zone of external oxide scale, the enrichment in $\mathrm{Mn}$ is also observed. Close to oxide scale/base material interface (around $400 \mathrm{~s}$ of sputtering), a co-enrichment of $\mathrm{Si}$ and $\mathrm{Ti}$ is observed. With increasing sputtering time, zone of Mn depletion is observed between 400 and $1300 \mathrm{~s}$.

The obtained GD-OES depth profile for alloy ground by 1000 grit sandpaper (Fig. 3b) looks similar, i.e., the external oxide scale consists of mixture of $\mathrm{Cr}, \mathrm{Fe}$ and $\mathrm{Mn}$. At the oxide scale/alloy interface, the enrichment of $\mathrm{Si}$ and $\mathrm{Ti}$ is observed. However, stronger enrichment in $\mathrm{Mn}$ in the external zone and deeper depletion zone is observed as compared with polished 
sample. Moreover, no enrichment in $\mathrm{Fe}$ is observed in the very outer part of the oxide scale as found for polished sample.

Depth profile obtained for 80 grit ground sample qualitatively looks very similar to this obtained for 1000 grit prepared surface. The difference is in outer oxide scale composition, i.e., higher content of $\mathrm{Cr}$ than $\mathrm{Fe}$ is found in the zone of external oxide scale. Additionally, two peaks in Ti line are found, first in the outer part of the oxide scale and second near the oxide scale/alloy interface. Also, higher enrichment of $\mathrm{Si}$ in the oxide scale/alloy interface is found similar like in case of 1000 grit or $1 \mathrm{um}$ surface finishing. Moreover, shorter sputtering time of external oxide scale is found for both ground samples (about $300 \mathrm{~s})$ than for polished one (400 s).

The SEM/BSE images of top surface of studied material with different surface preparations (Fig. $4 a, b$ and c) showed that a relatively flat region can be observed on all surfaces (marked by blue arrows) and nodules of oxides are also present (marked by red arrows). SEM/EDS point measurements revealed that flat regions are enriched in $\mathrm{Cr}$ and $\mathrm{Mn}$, while nodules are rich in $\mathrm{Fe}$ and $\mathrm{Cr}$. However, as can be seen, an amount of $\mathrm{Fe} / \mathrm{Cr}$-rich nodules decreases with increasing value of $\mathrm{R}_{\mathrm{a}}$ of studied materials (compare Fig. $4 \mathrm{a}, \mathrm{b}$ and c). Moreover, SEM/BSE elemental mapping performed on all studied surfaces during isothermal oxidation test confirmed the latter statement (see Fig. 5a, b and c). Elemental maps confirmed that nodules are co-enriched in $\mathrm{Fe}$ and $\mathrm{Cr}$, while flat regions contain $\mathrm{Cr}$ and $\mathrm{Mn}$. Additionally, local enrichments in Ti can be observed on all analyzed surfaces. Performed phase analyzes by XRD first of all revealed that all analyzed samples consist of similar phases (Fig. 6). The present phases on surface of isothermally oxidized were identified to be $\mathrm{Fe}_{2} \mathrm{O}_{3}, \mathrm{Fe}_{3} \mathrm{O}_{4}$, $\mathrm{Cr}_{2} \mathrm{O}_{3}, \mathrm{SiO}_{2}$ and spinels: $(\mathrm{Fe}, \mathrm{Cr})_{3} \mathrm{O}_{4}$ and $(\mathrm{Cr}, \mathrm{Mn})_{3} \mathrm{O}_{4}$ (Fig. 6). Combination findings by XRD and SEM/EDS elemental maps, it can be concluded that flat regions (marked by blue arrows in Fig. 4) consist of mixture of $\mathrm{Cr}_{2} \mathrm{O}_{3},(\mathrm{Cr}, \mathrm{Mn})_{3} \mathrm{O}_{4}$ and possibly $(\mathrm{Fe}, \mathrm{Cr})_{3} \mathrm{O}_{4}$, while $\mathrm{Fe}$-enriched nodules are the most probably mixed $\mathrm{Fe}_{2} \mathrm{O}_{3}, \mathrm{Fe}_{3} \mathrm{O}_{4}$ and likely $(\mathrm{Fe}, \mathrm{Cr})_{3} \mathrm{O}_{4}$. Formation of internally oxidized precipitates of $\mathrm{SiO}_{2}$ was confirmed by XRD as well.

The images of the cross sections of samples after isothermal oxidation are shown in Fig. 7(a), (b) and (c). One can observe that sample with polished surface is characterized by $\mathrm{Fe} / \mathrm{Cr} / \mathrm{Mn}$ rich oxide formation (the most probably mixture of $\mathrm{Cr}_{2} \mathrm{O}_{3}$, $(\mathrm{Cr}, \mathrm{Mn})_{3} \mathrm{O}_{4}$ and $\left.(\mathrm{Fe}, \mathrm{Cr})_{3} \mathrm{O}_{4}\right)$ with local presence of Fe-rich oxide nodules (mixture of $\mathrm{Fe}_{2} \mathrm{O}_{3}$ and $\mathrm{Fe}_{3} \mathrm{O}_{4}$ ) (Fig. 7a). Additionally, formation of internally oxidized $\mathrm{SiO}_{2}$ along grain boundaries is observed. Several pores and cracks in the external oxide scale are observed. Oxide scale formed on sample with 1000 grit surface preparation (Fig. 7b) is thinner in comparison with polished sample. Formation of $\mathrm{SiO}_{2}$ near the oxide scale/ alloy interface is observed as well; however, $\mathrm{SiO}_{2}$ precipitates are located just below external oxide scale and it seems that they are not incorporated as strongly with alloy grain boundaries as in case of polished alloy. Cross section image of alloy with 80 grit surface preparation (Fig. 7c) revealed that the sample formed thin and compact oxide scale consisting mainly of $\mathrm{Cr} / \mathrm{Fe} / \mathrm{Mn}$ mixed oxide, below which $\mathrm{SiO}_{2}$ precipitates can be found. Thickness of formed oxide scale in case of ground specimens is about $5 \mu \mathrm{m}$. Combination of findings by GD-OES (Fig. 3a, b and c), XRD (Fig. 6) and SEM/EDS point analyses led to conclusion that just at the bottom of external oxide scale, formation of $\mathrm{Cr}_{2} \mathrm{O}_{3}$ sub-layer is observed (as marked in Fig. 7a, $\mathrm{b}$ and $\mathrm{c}$ ). As shown on SEM/EDS spectra, outer oxide scale
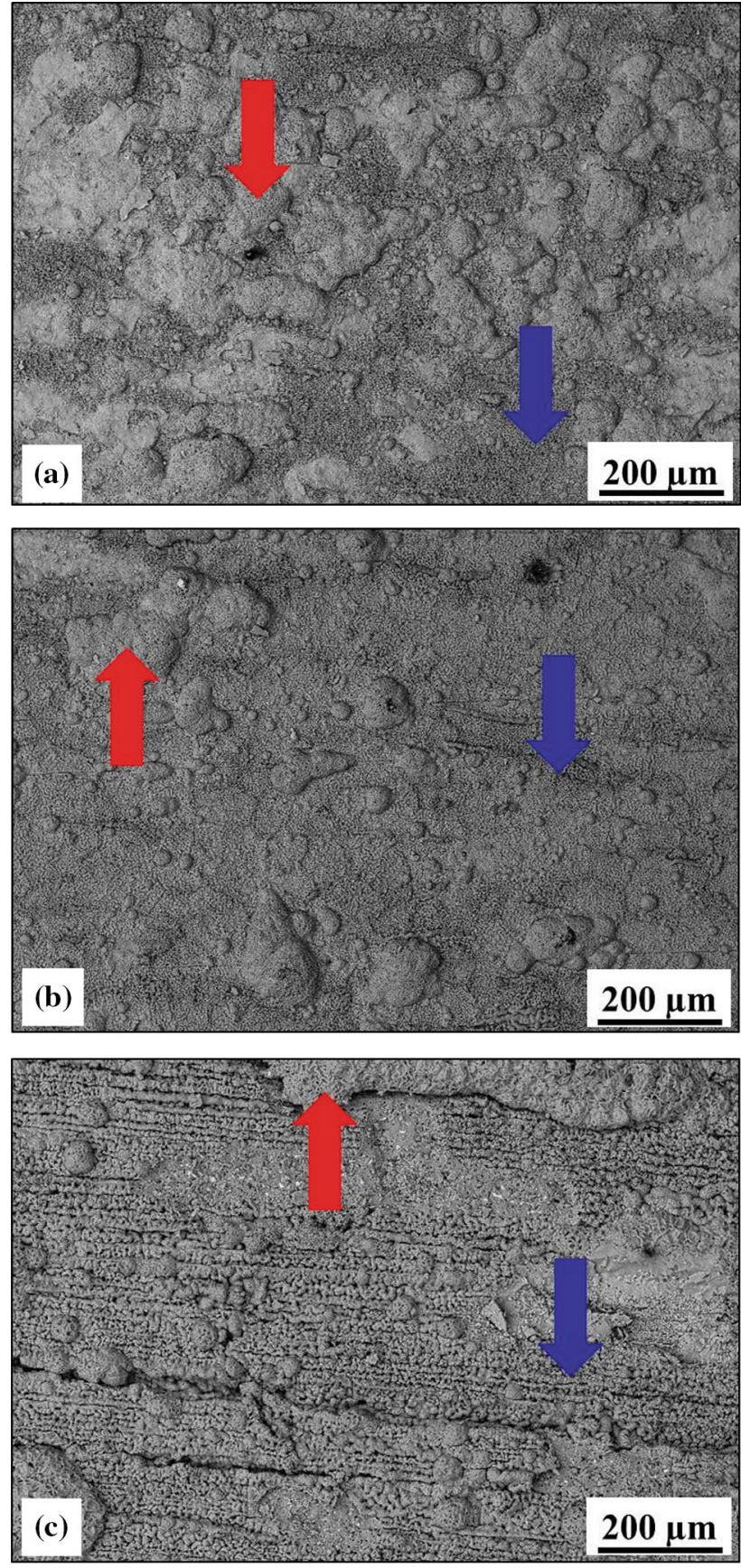

Fig. 4 SEM/BSE images of surfaces of studied material with: (a) polished, (b) ground with 1000 grit and (c) ground using 80 grit sandpaper after isothermal air oxidation at $1000{ }^{\circ} \mathrm{C}$ for $48 \mathrm{~h}$. Blue arrows indicate regions enriched in $\mathrm{Cr}$ and $\mathrm{Mn}$, while red arrows show formed oxide nodules enriched in $\mathrm{Fe}$

contains mainly $\mathrm{Fe}, \mathrm{Cr}$ and $\mathrm{Mn}$ (Fig. 7d), while dark precipitates are enriched in $\mathrm{Si}$ (Fig. 7e). The latter strongly supports statement about formation of $\mathrm{SiO}_{2}$ as internally oxidized precipitates.

\subsection{Cyclic Oxidation test at $1000^{\circ} \mathrm{C}$ : Slow Cycling}

To investigate the effect of surface preparation method on oxidation resistance of AISI 316 Ti, at first step cyclic oxidation test at $1000{ }^{\circ} \mathrm{C}$ was performed. The mass change obtained for alloy with polished and ground surfaces is shown in Fig. 8. The 

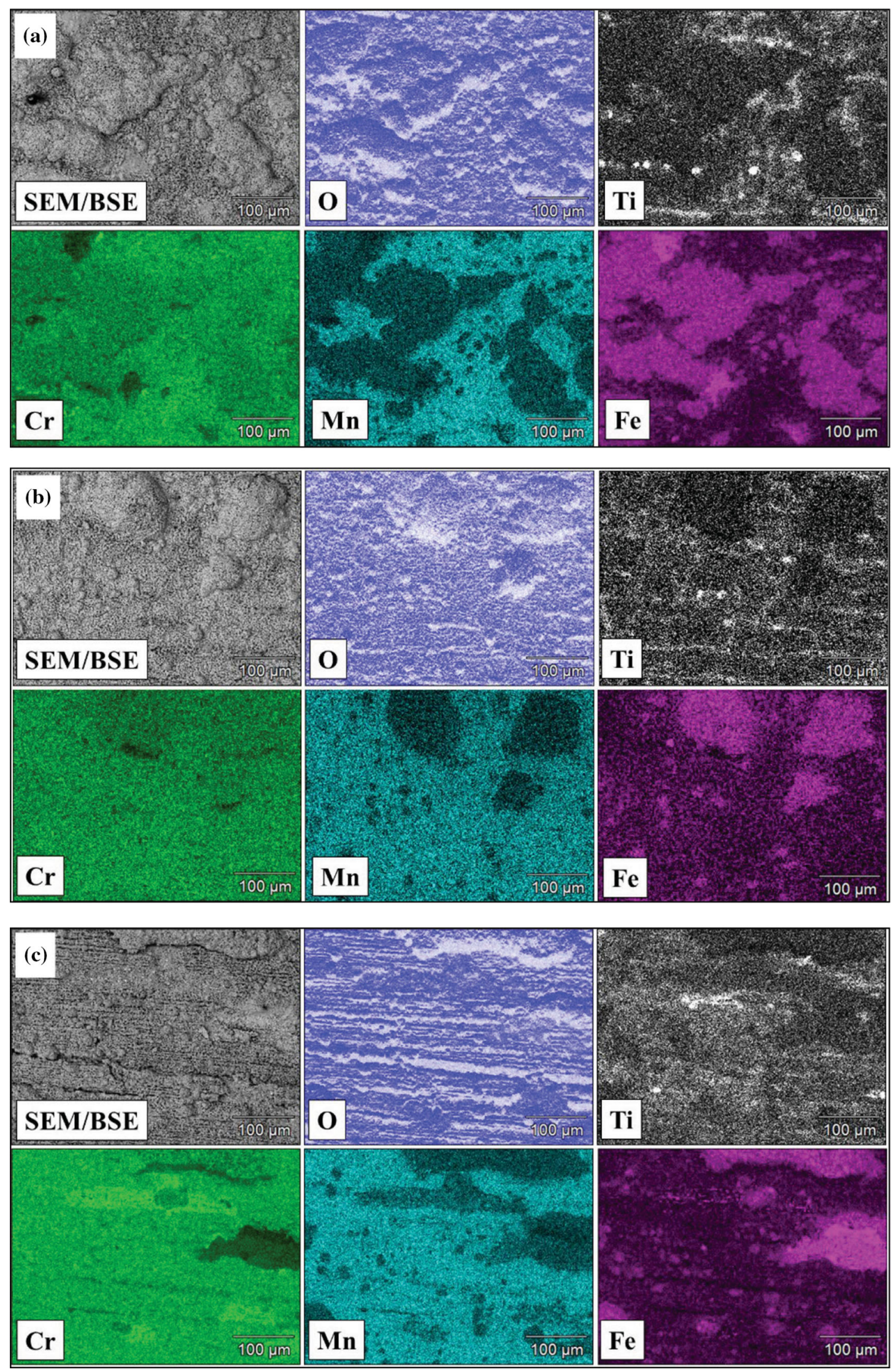

Fig. 5 SEM/BSE elemental maps obtained on surfaces of studied material with: (a) polished, (b) ground with 1000 grit and (c) ground using 80 grit sandpaper after isothermal air oxidation at $1000{ }^{\circ} \mathrm{C}$ for $48 \mathrm{~h}$ 
Fig. 7 SEM images of the cross sections of: (a) $1 \mu \mathrm{m}$ polished, (b) 1000 grit and (c) 80 grit ground surface, (d) SEM/EDS point analysis of region I from Fig. $4 \mathrm{~b}$ and e) SEM/EDS point analysis of region II from Fig. 4(b) of AISI 316Ti after isothermal exposure at $1000{ }^{\circ} \mathrm{C}$ in air

obtained results revealed that the samples with rougher surface revealed smaller mass loss at the end of the test. Namely, after 344 cycles (860 hot hours) the sample with surface ground using 80 grit sandpaper showed mass change equal to $-5.8 \mathrm{mg} \mathrm{cm}^{-2}$, ground with 1000 grit sandpaper $-12.5 \mathrm{mg} \mathrm{cm}^{-2}$ and with polished surface $-33.6 \mathrm{mg} \mathrm{cm}^{-2}$. Thus, the rougher surface preparation resulted in higher oxidation resistance in this type of cyclic oxidation test.

\subsection{Cyclic Oxidation test at $900^{\circ} \mathrm{C}$ : Slow Cycling}

To investigate the effect of surface geometry on oxidation resistance at temperature closer to application temperature of AISI $316 \mathrm{Ti}$, a cyclic oxidation at $900{ }^{\circ} \mathrm{C}$ was done. The obtained mass change is shown in Fig. 9. One can observe a similar trend like in case of exposure at $1000{ }^{\circ} \mathrm{C}$, namely the sample with polished surface showed the highest mass loss at the end of cyclic oxidation $\left(-27.5 \mathrm{mg} \mathrm{cm}^{-2}\right)$, with surface ground using 1000 grit sandpaper showed mass loss of $-7.7 \mathrm{mg} \mathrm{cm}^{-2}$ and with surface ground by 80 grit sandpaper the mass loss was equal to $-2.2 \mathrm{mg} \mathrm{cm}^{-2}$. Thus, the trend is similar as observed during slow cycling oxidation test at $1000{ }^{\circ} \mathrm{C}$.

\subsection{Cycling Oxidation Test at $900^{\circ} \mathrm{C}$ : Rapid Cycling}

To evaluate the effect of cycles frequency on oxidation resistance of AISI 316 Ti, an accelerated cyclic oxidation was performed at $900{ }^{\circ} \mathrm{C}$ with as called rapid cycling. The mass change obtained during this type of cyclic oxidation is shown in Fig. 10. The obtained results revealed similar influence of surface roughness on oxidation resistance as in both slow cycling tests. The mass loss measured at the end of the test $(100$ cycles, i.e., 200 hot hours) of alloy with 80 grit ground surface was $-27.8 \mathrm{mg} \mathrm{cm}^{-2}$, for surface ground with 1000 grit sandpaper was $-37 \mathrm{mg} \mathrm{cm}^{-2}$ and for polished surface $-42.6 \mathrm{mg} \mathrm{cm}^{-2}$. Then, despite value of mass change and

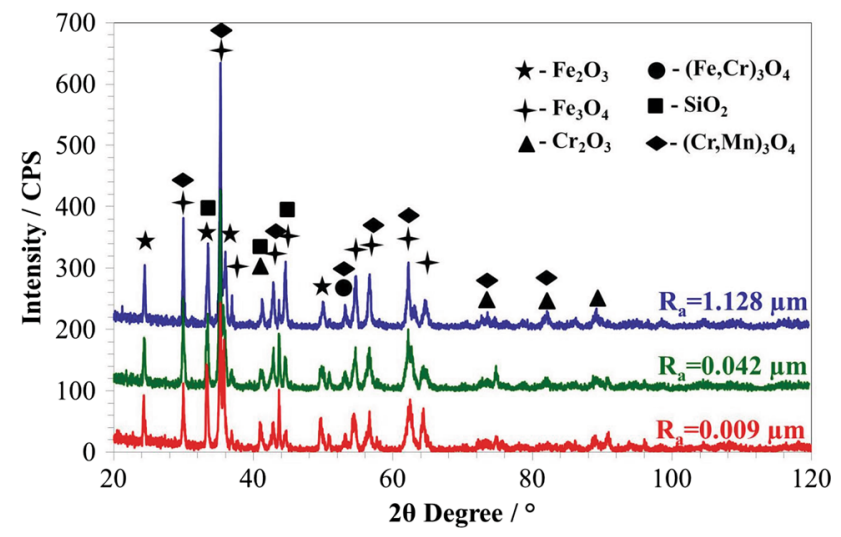

Fig. 6 XRD patterns obtained on surfaces of studied material with polished, ground with 1000 grit and ground using 80 grit sandpaper after isothermal air oxidation at $1000{ }^{\circ} \mathrm{C}$ for $48 \mathrm{~h}$
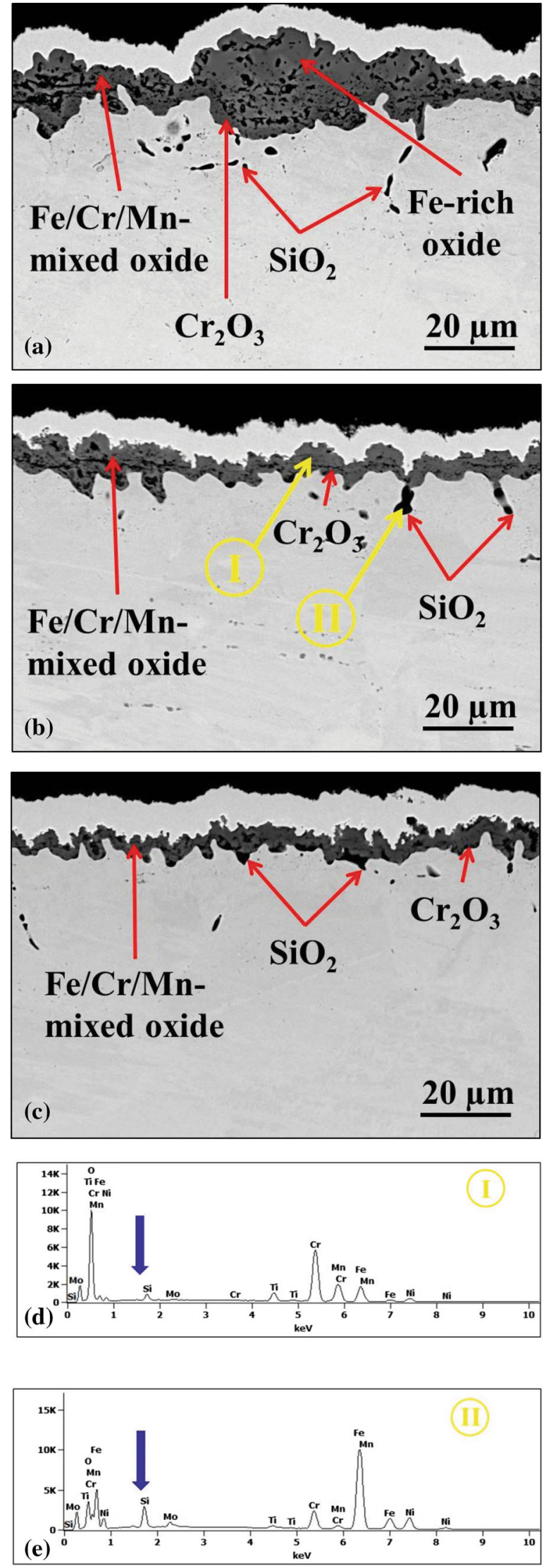
difference in total cycles number, the trend in role of surface roughness on oxidation resistance is similar like in both mentioned slow cyclic tests.

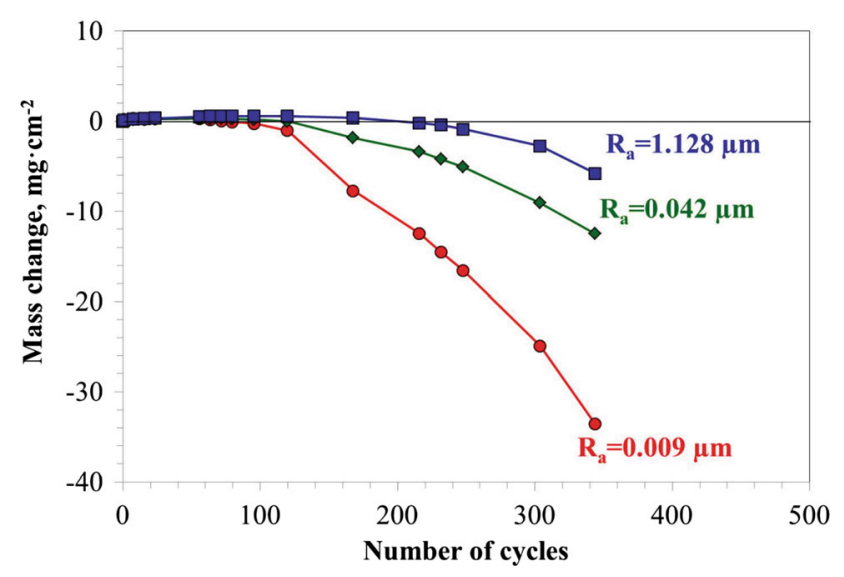

Fig. 8 Mass change plot obtained during cyclic oxidation test of AISI $316 \mathrm{Ti}$ at $1000^{\circ} \mathrm{C}$ in air (slow cycling)

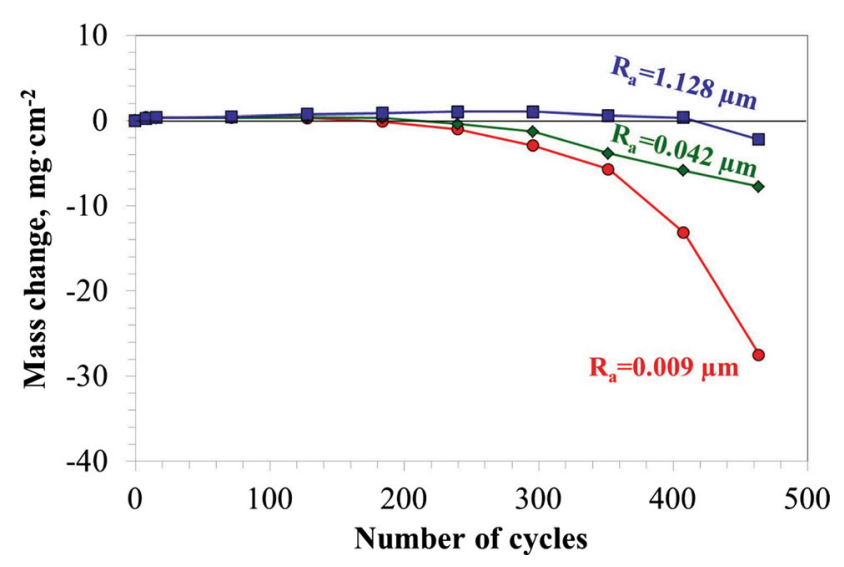

Fig. 9 Mass change plot obtained during cyclic oxidation test of AISI $316 \mathrm{Ti}$ at $900{ }^{\circ} \mathrm{C}$ in air (slow cycling)

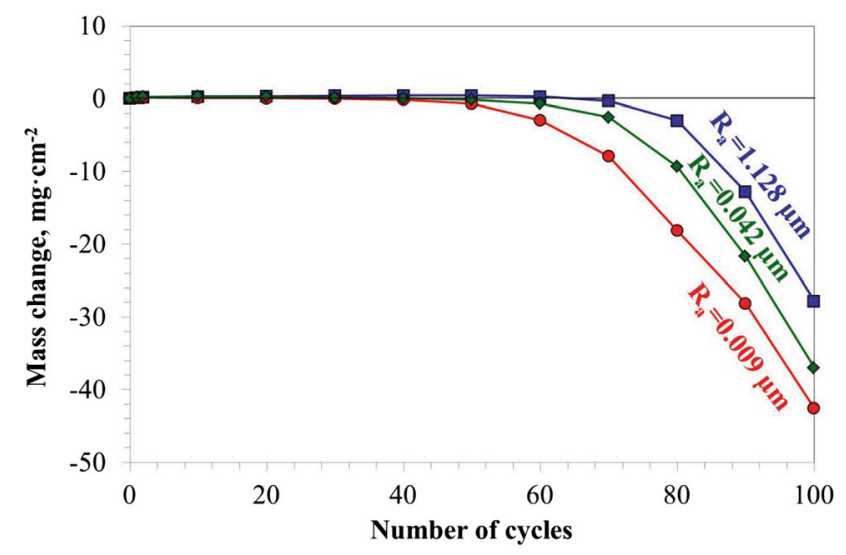

Fig. 10 Mass change plot obtained during cyclic oxidation test of AISI 316Ti at $900^{\circ} \mathrm{C}$ in air (rapid cycling)

\section{Discussion}

All kinds of cyclic oxidation tests performed in the present work revealed the tendency that studied AISI 316Ti with higher surface roughness showed better oxidation resistance. As indication of the latter, the smallest mass loss caused by oxide scale spallation was assumed. The clear correlation between sandpaper gradation used for surface preparation and the obtained mass change curves was observed (see Fig. 8, 9 and 10). As mentioned previously, in all cyclic oxidation tests, the smallest mass loss at the end of the tests was observed for samples ground with 80 grit sandpaper, medium for 1000 grit sandpaper and the highest mass loss for samples with surfaces polished up to $1 \mu \mathrm{m}$ silica suspension. To explain the latter, one should observe the results of isothermal oxidation. The mass change curves revealed the highest mass gain obtained for alloy with polished surface, while for both ground surfaces lower mass change was found (see Fig. 2). The results of chemical composition of formed oxide scale showed that on all surfaces mixed $\mathrm{Fe} / \mathrm{Cr} / \mathrm{Mn}$ external oxide scale was formed accompanied with zone of internally oxidized $\mathrm{SiO}_{2}$ precipitates. The difference, however, was, that in case of sample with polished surface, in the outer part of external oxide, higher amount of $\mathrm{Fe}$ was found. Moreover, internally oxidized $\mathrm{SiO}_{2}$ precipitated at the grain boundaries is localized at quite big depth, while for both ground surfaces $\mathrm{SiO}_{2}$ precipitates were found at the bottom of external oxide scale. Additionally, the longer sputtering time was noticed for sample with polished surface than for both ground. This suggests the formation of thicker oxide scale. The BSE/SEM images of the cross sections of isothermally oxidized specimens confirmed this finding. Local formation of nodules was found on polished samples. SEM/ EDS elemental map shown in Fig. 12 revealed that outer part of formed nodule is enriched in Fe, while at the bottom of the oxide scale $\mathrm{Cr} / \mathrm{Mn}$ mixed oxide is formed. Just below $\mathrm{Cr} / \mathrm{Mn}$ mixed oxide, the precipitates rich in $\mathrm{Si}$ are observed. Considering the fact that GD-OES depth profiling is done using $4 \mathrm{~mm}$ diameter anode then the measured signal shows an average value of element concentration. Then, the increased content of $\mathrm{Fe}$ in the outer part of external oxide scale measured on polished sample after isothermal oxidation up to $48 \mathrm{~h}$ is most likely caused by the formation of mentioned Fe-enriched nodules. Since Fe-oxides growth rate is much higher that $\mathrm{Cr} /$ Mn-mixed oxide, then the sample which forms Fe-rich oxide will reach earlier so called "critical oxide scale thickness" (Ref 31 ) and in this case the spallation occurs faster. The isothermal oxidation tests results showed the formation of thicker oxide scale on polished samples, then oxide scale spallation is likely to occur faster on polished samples and it is delayed on ground samples. Moreover, lower paper gradation (higher surface roughness) resulted in longer delay in oxide scale spallation. Such phenomenon was observed in all performed cyclic oxidation tests independently on cycling rate and temperature. In previous studies Gusak et al. (Ref 32) proved that the presence of backstresses significantly influences the mass transport in diffusion couple. Nazarov (Ref 33) showed that the presence of internal stresses increases the effective grain boundaries diffusion coefficient. To elucidate the reason for different oxidation behavior of material with differently prepared surface, a residual stress measurement was performed. A high purity model alloy $\mathrm{Fe}-10 \mathrm{Cr}$ (wt.\%) was the material used for determination of the effect of mechanical surface prepara- 
tion on residual stress. Investigation of high purity model alloy allows to avoid the possible effect of complex chemical composition on residual stress. At first stage, three samples were equally prepared by grinding up to 2400 grit sandpaper. Then, the samples were heat-treated at $615^{\circ} \mathrm{C}$ for $6 \mathrm{~h}$ in high purity argon atmosphere for removal of residual stresses originating, e.g., from casting and solidification. After heattreatment procedure, each sample was described for different surface preparations, and the residual stresses were determined at "relaxed" stage. After that, each prescribed sample was subjected for proper mechanical surface preparation, i.e., polishing, grinding using 1000 grit and 80 grit sandpapers. After surface preparation, the residual stresses were measured exactly on the same samples. The results of residual stresses caused only by surface preparation are shown in Fig. 11. A blue

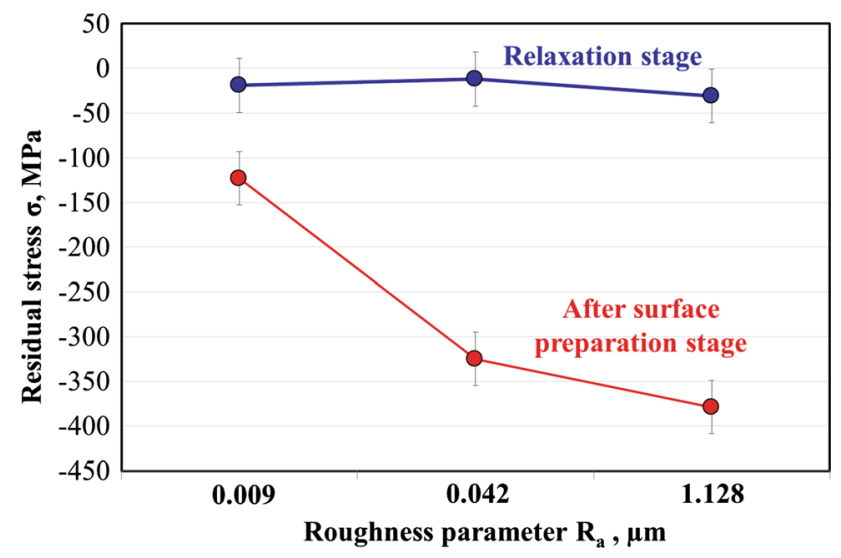

Fig. 11 Results of measured residual stresses on $\mathrm{Fe}-10 \mathrm{Cr}$ samples at stage after relaxation heat-treatment and after different mechanical surface preparation methods curve shows the residual stresses measured after relaxation heat-treatment, while red curve shows the residual stresses measured on the same samples but after mechanical surface preparation. Presentation of blue curve as function of $R_{\mathrm{a}}$ might be misleading, because the samples after heat-treatment possessed exactly the same roughness. Showing the points as function of $R_{\mathrm{a}}$ is done only to show that the residual stress was measured exactly on the same sample and to present clear dependence between surface mechanical preparation and measured residual stresses. One can clearly see that increase in $R_{\mathrm{a}}$ results in more negative values (compressive) of residual stresses (see Fig. 11). The latter observation in combination with observation by Gusak and Nazarov leads to conclusion that in present study more negative residual stresses lead to increase in diffusion coefficient of elements forming protective oxide scales like $\mathrm{Cr}$ and $\mathrm{Mn}$, the most probably due to increase in grain boundaries density (recrystallization process). In case of polished surface, less protective oxide scale formed, namely Fe-rich oxide, which allows oxygen penetration into the bulk alloy and caused formation of Si-rich oxides at the grain boundaries (see Fig. 7a). For both ground surfaces formation of more protective oxide scales, namely $\mathrm{Fe} / \mathrm{Cr} / \mathrm{Mn}$ mixed oxide was found. Formation of such protective and continuous oxide scale resulted in lowering the gradient of $\mathrm{pO}_{2}$ along the oxide scale and consequently, formation of Si-rich precipitates just below external $\mathrm{Fe} / \mathrm{Cr} / \mathrm{Mn}$ mixed oxide scale (Fig. 10b and c). The latter was confirmed by obtained GD-OES depth profiles (Fig. 3a, b and c) which clearly shows the increase in $\mathrm{Si}$ concentration below the outer oxide scale.

Another proposed explanation of different oxidation behavior of studied material is that more rough surface preparation introduces higher amount of defects which can act as an easy diffusion path for the elements forming protective oxide scale ( $\mathrm{Cr}, \mathrm{Mn}$ and $\mathrm{Si}$ in the present case) as it was already proposed in previous works ( $\operatorname{Ref} 21-24,34)$.
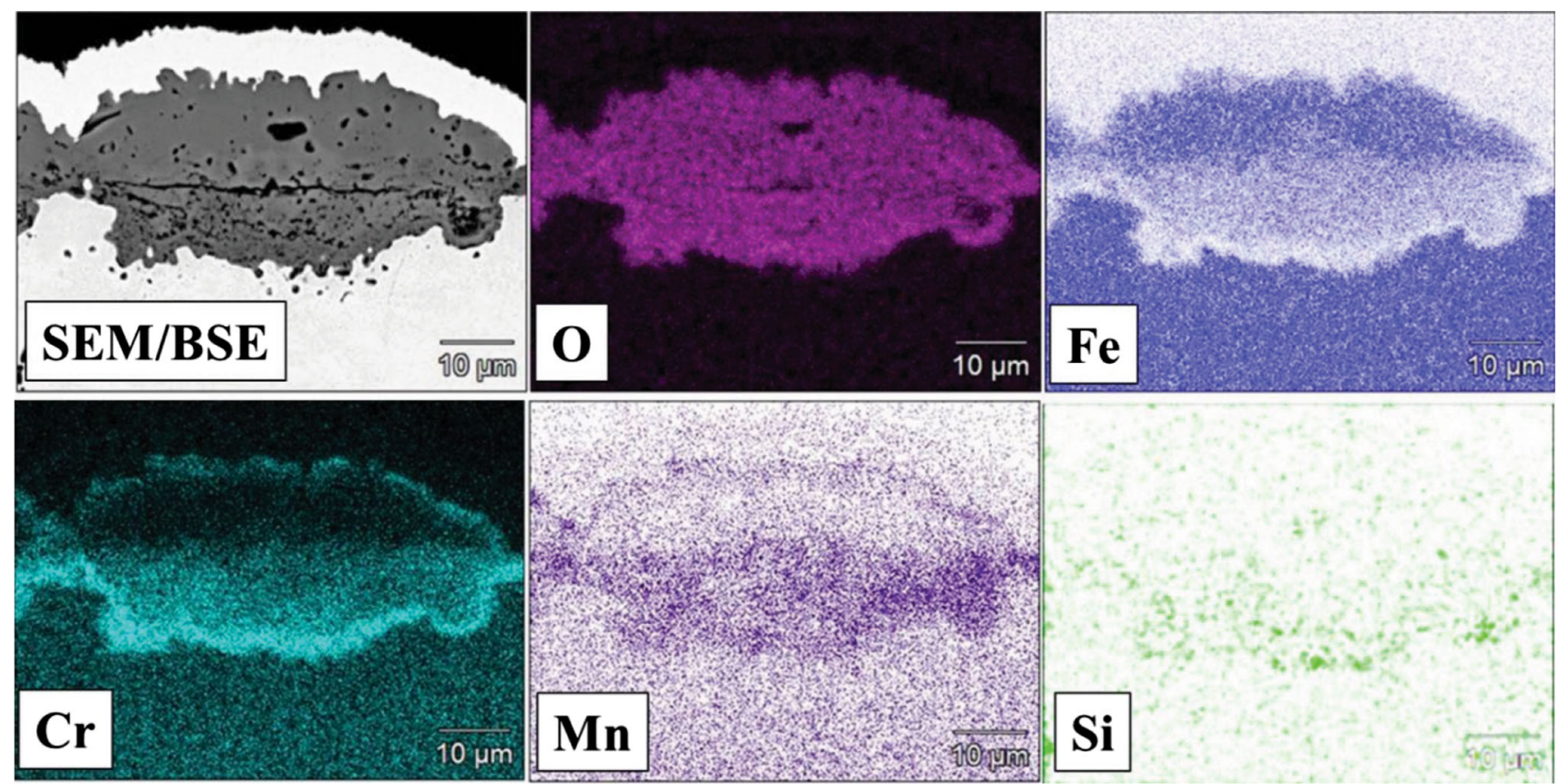

Fig. 12 SEM/BSE image and corresponding SEM/EDS elemental maps performed on formed nodule on AISI $316 \mathrm{Ti}$ with $1 \mu \mathrm{m}$ polished surface after isothermal air exposure for $48 \mathrm{~h}$ 


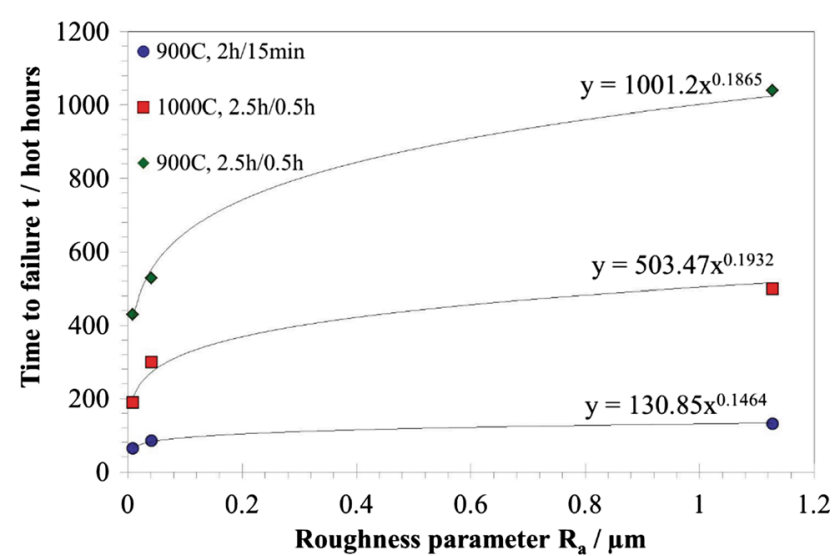

Fig. 13 Plot showing time-to-failure as function of surface roughness calculated based on mass change plots shown in Fig. 8, 9 and 10

For quantitative description of the influence of surface geometry in term of surface roughness, time-to-failure was calculated for each specimen tested in all kind of cyclic oxidation test. As a failure, time needed for reaching "zero" mass change for each tested specimen was assumed. In other words, based on the mass change plots shown in Fig. 8, 9 and 10 , the time at which the mass change curves crossed a zero mass change $\left(\mathrm{mg} \mathrm{cm}^{-2}\right)$ was read for each tested specimen. The results are shown in Fig. 13. It is clear from the Fig. 13 that the samples with surfaces ground by 80 grit sandpaper revealed the longest time to failure for each cyclic oxidation tests, while polished samples showed the shortest time to failure. It is also visible that for the same cyclic conditions ( $2.5 \mathrm{~h}$ heating, $0.5 \mathrm{~h}$ cooling) increase in temperature from 900 to $1000{ }^{\circ} \mathrm{C}$ results obviously in shortening of time-to-failure, e.g., for sample with surface ground with 80 grit sandpaper from about 1000 hot hours at $900{ }^{\circ} \mathrm{C}$ to 400 hot hours at $1000{ }^{\circ} \mathrm{C}$ (see Fig. 13). Additionally, change in cycle condition from "slow cycling" $(2.5 \mathrm{~h}$ heating, $0.5 \mathrm{~h}$ cooling) to rapid cycling ( $2 \mathrm{~h}$ heating, $15 \mathrm{~min}$ cooling with pressurized air) caused even higher drop in time to failure than increasing temperature. Namely, for 80 grit ground sample time-to-failure has been shortened from 1000 hot hours for "slow cycling" to 100 hot hours for "rapid cycling," for 1000 grit ground surface from 500 hot hours to 80 hot hours and for polished surface from 400 to 60 hot hours. Then, one should notice that rougher surface results in elongation of time-to-failure, however, these type of samples are more sensitive to changes of cyclic conditions in the way that more severe cyclic condition suppresses the positive influence of surface roughness on time to failure for studied alloy.

\section{Conclusions}

Based on the results obtained in the present work, following conclusions can be drawn:

1. Increase in surface roughness of AISI 316 Ti results in formation of more uniform and protective $\mathrm{Cr} / \mathrm{Mn}$ mixed oxide scale during short-term isothermal exposure. Smoothening of surface caused local formation of fast growing Fe-rich oxide nodules.
2. Elongation of time-to-failure was observed and correlated with increasing surface roughness. Such dependence was observed independently on cyclic conditions and temperature.

3. The observed dependence of time-to-failure on surface roughness can be correlated with differences in oxidation kinetics during short-term isothermal exposure. Namely, higher oxide scale growth rate shortens necessary time to obtain critical oxide scale thickness and speeds up oxide scale spallation process.

4. Increase in oxidation resistance, expressed by longer time-to-failure, was observed in all types of performed cyclic oxidation tests. However, frequency of cycling also influences the oxidation resistance of studied alloy. Namely, more severe cyclic condition suppresses the positive effect of surface roughness on sample lifetime.

5. As the most possible reason of increase in alloy lifetime by increased surface roughness combined effect of increase in internal residual stresses and introduction of defects in the near-surface region by mechanical surface preparation is proposed..

\section{Acknowledgments}

The Author is grateful to the M.Sc. Kamil Gancarczyk for performing XRD analyzes.

\section{Funding}

Project financed by the National Center for Research and Development (Narodowe Centrum Badan i Rozwoju) under the TECHMATSTRATEG2/406725/1/NCBR/2020 program.

\section{Open Access}

This article is licensed under a Creative Commons Attribution 4.0 International License, which permits use, sharing, adaptation, distribution and reproduction in any medium or format, as long as you give appropriate credit to the original author(s) and the source, provide a link to the Creative Commons licence, and indicate if changes were made. The images or other third party material in this article are included in the article's Creative Commons licence, unless indicated otherwise in a credit line to the material. If material is not included in the article's Creative Commons licence and your intended use is not permitted by statutory regulation or exceeds the permitted use, you will need to obtain permission directly from the copyright holder. To view a copy of this licence, visit http://creativecommons.org/licenses/by/4.0/.

\section{References}

1. C.S. Giggins and F.S. Pettit, Oxidation of Ni-Cr-Al Alloys between 1000 and 1200 C, Solid State Sci., 1971, 118(11), p 1782-1790

2. E.J. Opila, D.L. Mayers, N.S. Jacobson, I.M.B. Nielsen, D.F. Johnson, J.K. Olminsky, and M.D. Allendorf, High Temperature Corrosion of Alloys and Coatings, J. Phys. Chem. A, 1971, 2007, p 111

3. M. Stanislowski, J. Froitzheim, L. Niewolak, W.J. Quadakkers, K. Hilpert, T. Markus, and L. Singheiser, Reduction of Chromium Vaporization from SOFC Interconnectors by Highly Effective Coatings, J. Power Sour., 2007, 164, p 578-589 
4. Datasheet: Stainless Steel 1.4571-316Ti, Equinox International Ltd, pp. 1-3 (2012)

5. M. Sun, X. Wu, Z. Zhang, and E.-H. Han, Oxidation of 316 Stainless Steel in Supercritical Water, Corros. Sci., 2009, 51, p 1069-1072

6. R.D. Hanbury and G.S. Was, Oxide Growth and Dissolution on 316L Stainless Steel during Irradiation in High Temperature Water, Corros. Sci., 2019, 157, p 305-311

7. J. Wambach, A. Wokaun, and A. Hiltpold, Oxidation of Stainless Steel under Dry and Aqueous Conditions: Oxidation Behaviour and Composition, Surf. Interface Anal., 2002, 34(1), p 164-170

8. Z. Ren and F. Ernst, High-Temperature Phase Transformations in AISI, 316 Stainless Steel Infused with Concentrated Interstitial Carbon, $J$. Alloy. Compd., 2020, 819, p 153000

9. K. Rokosz, T. Hryniewicz, and G. Solecki, Comparative Corrosion Studies of 2205 Duplex Steel after Electropolishing and Passivation in Ringer's Solution, World Sci. News, 2018, 98, p 46-60

10. M. Schütze and W.J. Quadakkers, Future Directions in the Field of High-Temperature Corrosion Research, Oxid. Met., 2017, 87, p 681704

11. X. Hou, H. Zhang, M. Seraffon, and A.T. Fry, Steam Oxidation and Mechanical Performance of a Ferritic-Martensitic Steel with Slurry Aluminide Coating, Mater. Corros., 2020, 2020, p 1-11

12. M. Rabani, M. Zandrahimi, and H. Ebrahimifar, High Temperature Oxidation Behavior of Aluminide Coating Fabricated on UNS S30815 Stainless Steel, Int. J. ISSI, 2019, 16, p 41-50

13. J. Dong, Y. Sun, and F. He, Medium-Temperature Thermoelectric GeTe: Vacancy Suppression and Band Structure Engineering Leading to High Performance, Surf. Coat. Technol., 2019, 375(15), p 833-838

14. W.J. Nowak, K. Ochał, P. Wierzba, K. Gancarczyk, and B. Wierzba, Effect of Substrate Roughness on Oxidation Resistance of an Aluminized Ni-Base Superalloy, Metals, 2019, 9, p 782-795

15. G. Bolelli, C. Vorkötter, L. Lusvarghi, S. Morelli, V. Testa, and R. Vaßen, Performance of Wear Resistant MCrAlY Coatings with oxide Dispersion Strengthening, Wear, 2020, 15, p 444-445

16. X.Z. Zhang, X.J. Wu, R. Liu, and M.X. Yao, Effects of OxidationResistant Coating on Creep Behavior of Modified 9Cr-1Mo Steels, Mater. Sci. Eng., A, 2019, 743, p 418-424

17. G. Moskal, D. Niemiec, B. Chmiela, P. Kałamarz, T. Durejko, M Zietala, and T. Czujko, Microstructural Characterization of LaserCladded NiCrAlY Coatings on Inconel $625 \mathrm{Ni}$-Based Superalloy and 316L Stainless Steel, Surf. Coat. Technol., 2020, 387, p 125317

18. E. Hejrani, D. Sebold, W.J. Nowak, G. Mauer, D. Naumenko, R. Vassen, and W.J. Quadakkers, Isothermal and Cyclic Oxidation Behavior of Free Standing MCrAlY Coatings Manufactured by High-Velocity Atmospheric Plasma Spraying, Surf. Coat. Technol., 2017, 313, p 191-201

19. Pei et al., Influence of Surface Roughness on the Oxidation Behavior of a Ni-4.0 Cr-5.7 Al Single Crystal Superalloy, Appl. Surf. Sci., 2018, 2018, p 790-803
20. L. Wang et al., Effect of Surface Roughness on the Oxidation Behavior of a Directionally Solidified Ni-Based Superalloy at 1100 C, Acta Metall. Sin. (Engl. Lett.), 2015, 28(3), p 381-385

21. W.J. Nowak and B. Wierzba, Effect of Surface Treatment on HighTemperature Oxidation Behavior of IN 713C, J. Mater. Eng. Perform., 2018, 27(10), p 5280-5290

22. D. Serafin, W.J. Nowak, and B. Wierzba, Effect of Surface Mechanical Treatment on the Oxidation Behavior of FeAl-Model Alloy, Appl. Surf. Sci., 2019, 476, p 442-451

23. W.J. Nowak, D. Serafin, and B. Wierzba, J. Mater. Sci., 2019, 54(12), p 9185-9196

24. D. Serafin, W.J. Nowak, and B. Wierzba, Differences in Oxides Morphology as a Result of Surface Preparation of NiFe Alloy, Surf. Coat. Technol., 2020, 382, p 125421

25. S. Benafia, D. Retraint, S.Y. Brou, B. Panicaud, and J.L.G. Poussard, Influence of Surface Mechanical Attrition Treatment on the Oxidation Behaviour of 316L Stainless Steel, Corros. Sci., 2018, 136, p 188-200

26. P. Fajnor, T. Liptáková, and V. Konstantová, Influence of AISI, 316Ti Stainless Steel Surface Treatment on Pitting Corrosion in Various Solution, Mater. Eng., 2010, 17(3), p 21-27

27. T. Liptáková, A. Alaskari, L. Trško, and S. Dundeková, Corrosion Resistance of AISI, 316Ti Stainless Steel Subjected to Shot Peening with and without Pickling in Various Chloride Environments, Trans. FAMENA, 2017, 2017, p 81-90

28. J.P. Pfeifer, H. Holzbrecher, W.J. Quadakkers, and J. Speier, Quantitative Analysis of Oxide Films on ODS-Alloys Using MCs + SIMS and e-Beam SNMS, Fresenius' J. Anal. Chem., 1993, 346, p 186-191

29. W.J. Quadakkers, A. Elschner, W. Speier, and H. Nickel, Composition and Growth Mechanisms of Alumina Scales on FeCrAl-Based Alloys Determined by SNMS, Appl. Surf. Sci., 1991, 52, p 271-287

30. W.J. Nowak, Characterization of Oxidized Ni-Based Superalloys by GD-OES, J. Anal. At. Spectrom., 2017, 32, p 1730-1738

31. P.Y. Hou and R.M. Cannon, Spallation Behavior of Thermally Grown Nickel Oxide on Nickel, Oxid. Met., 2009, 71, p 237-256

32. A. Gusak, B. Wierzba, and M. Danielewski, Competition Between Kirkendall Shift and Backstress in Interdiffusion Revisited: Simple Analytic Model, Philos. Magn., 2014, 94(10), p 1153-1165. https:doi. org/10.1080/14786435.2013.878053

33. A.A. Nazarov, Internal Stress Effect on Grain-Boundary Diffusion in Submicrocrystalline Metals, Philos. Mag. Lett., 2000, 80(4), p 221227. https:doi.org/10.1080/095008300176191

34. J.N. Wojciech, S. Krzysztof, O. Kamil, K. Barbara, and W. Bartek, Consequences of Different Mechanical Surface Preparation of Ni-Base Alloys during High Temperature Exposure, Materials, 2020, 13, p 3529. https:doi.org/10.3390/ma13163529

Publisher's Note Springer Nature remains neutral with regard to jurisdictional claims in published maps and institutional affiliations. 